\title{
Metachronous Second Primary Colonic Malignancy after Pancreaticoduodenectomy for Ampullary Malignancy: Report of Two Cases
}

\author{
Niket M Shah, Sankar Subramanian, Sureshkumar Palanichamy, Neelendra Yasaswy \\ Department of Surgical Gastroenterology, Sriramachandra Institute of Higher Education \& Research, Chennai, Tamil Nadu, India.
}

\section{Corresponding Author: \\ Dr Niket M Shah \\ Email: nikk240488@gmail.com}

This is an Open Access article distributed under the terms of the Creative Commons Attribution License (creativecommons.org/ licenses/by/3.0).

Received : June 27, 2020

Accepted : July 28,2020

Published : September 5, 2020

\begin{abstract}
Background: Ampullary and colonic malignancies share common environmental and genetic factors. Ampullary cancer as a second primary malignancy after colorectal cancer has been reported frequently in literature in familial adenomatous polyposis (FAP) and hereditary non-polyposis colon carcinoma, but published reports of metachronous second primary colonic malignancy after the pancreatico-duodenectomy for ampullary malignancy are less. Here we present two cases of metachronous second primary colonic malignancy after index surgery for ampullary malignancy. Methods and Results: Two patients underwent pancreatico-duodenectomy for ampullary malignancies and subsequently developed metachronous $2^{\text {nd }}$ primary colonic malignancy after an interval of 36 and 60 months from first surgery respectively. Clinical data and management were analysed retrospectively and prospectively. Both patients underwent colonic resection followed by adjuvant chemotherapy. Conclusion: Patients with ampullary cancer have an increased risk of developing a subsequent primary colorectal cancer and vice versa. Screening colonoscopy should be strongly recommended to patients who have received curative therapy for ampullary cancer.
\end{abstract}

Keywords: Ampulla of Vater, Chemotherapy, Colorectal Neoplasms, Colonoscopy, Neoplasms.

\section{Introduction}

There are theories and evidences to prove that ampullary and colonic malignancies are related to one another. The sequence of progression from benign tumor to carcinoma for ampullary neoplasms closely resembles the sequence discovered in colonic malignancies [1-3]. Third, epidemiological studies suggest a possible two-way association between these two forms of malignancies.

The published reports of subsequent primary malignancy in patients with cancer of the ampulla of Vater are limited [4]. Ampullary cancer as a second primary malignancy in patients with colorectal cancer has been reported frequently in literature in patients with familial adenomatous polyposis (FAP) [5] and with hereditary non- polyposis colon cancer [6]. Recent improvements in the prognosis of cancer patients have led to a rise in the incidence and the frequency of multiple primary malignant tumors. Here we present case reports of two patients who underwent pancreaticoduodenenctomy for ampullary malignancies and afterwards developed $2^{\text {nd }}$ primary metachronous colonic malignancy years later that was managed by surgical resection and adjuvant chemotherapy.

\section{Case Reports}

Two patients underwent pancreatico-duodenectomy for ampulary malignancies and subsequently metachronous $2^{\text {nd }}$ primary colonic malignancy after an interval of 36 months and 60 months from first surgery respectively. Clinical data and management were analysed retrospectively and prospectively [Table 1]. 


\section{Case 1}

In year 2006, 46 years old man was admitted at our hospital for jaundice and pruritus of 2 months duration with liver function tests suggestive of obstructive jaundice. Endoscopy showed ampullary lesion which was suggestive of moderately differentiated adenocarcinoma. CT abdomen showed ampullary mass lesion causing upstream bile duct and pancreatic duct dilatation and distended gall bladder with few regional lymph nodes. Patient underwent pancreaticoduodenectomy. Histopathology revealed well differentiated adenocarcarcinoma [pT2N0M0] and chemotherapy was not advised. After initial follow up visits, patient was lost to follow up. Three years after index surgery, patient came to hospital with abdominal distension, constipation and vomiting. CT abdomen showed circumferential wall thickening and annular mass in splenic flexure of colon with mesocolic lymphadenopathy with normal pancreatic bed [Fig.1]. The patient was diagnosed to have metachronous new primary splenic flexure colonic malignancy with colonic obstruction. Intraoperatively small bowel and right sided colon were found to be dilated. Subtotal colectomy with ileo-sigmoid anastomosis was done. Histopathology was suggestive of moderately differentiated adenocarcinoma [pT3pN2Mx]. Subsequently patient was subjected to adjuvant chemotherapy for 1.5 years, but developed locoregional and distant metastasis suggestive of aggressive behaviour of malignancy.

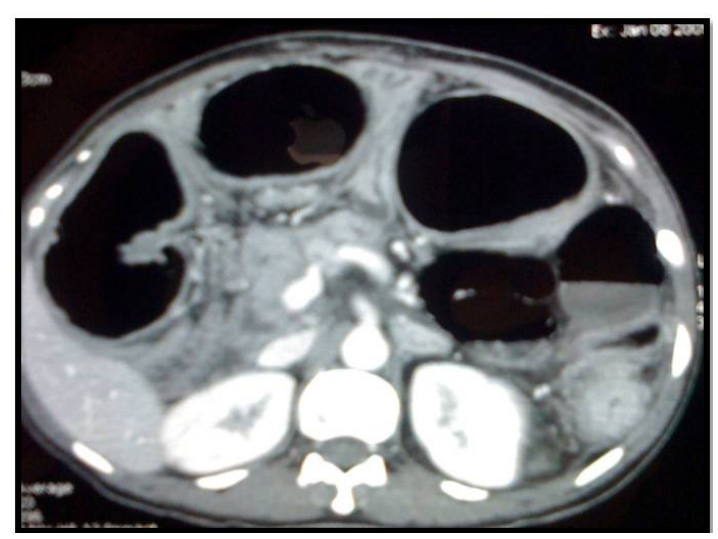

Fig.1: CT abdomen showing circumferential splenic flexure thickening with near complete obstruction.

\section{Case 2}

In 2014, 57 years old man was admitted with complaints of high colored urine and yellowish discoloration of eyes of 2 months duration. On endoscopy and CT evaluation, patient was diagnosed to have ampullary moderately differentiated adenocarcinoma, T2N0M0. Patient underwent pancreatico-duodenectomy for the same. Histopathology was suggestive of moderately differentiated adenocarcinoma pT3pN0Mx and adjuvant chemotherapy was not advised. Patient was lost to follow up after initial few visits. 5 years later from index surgery, patient came to hospital with breathing difficulty and easy fatigability. On PET-CT scan, patient was found to have FDG avid enhancing mass lesion within hepatic flexure of colon with pericolic lymphadenopathy and normal pancreatic bed [Fig.2]. Further colonoscopy showed ulcero-proliferative circumferential lesion

Table 1: Clinical and outcome data of our patients.

\begin{tabular}{|c|c|c|c|c|c|c|c|}
\hline S. No. & Age/sex & Primary malignancy & $\begin{array}{l}\text { Adjuvant } \\
\text { chemotherapy }\end{array}$ & Interval & $2^{\text {nd }}$ primary malignancy & Phase & $\begin{array}{l}\text { Survival \& } \\
\text { Outcome }\end{array}$ \\
\hline 1. & $46 / \mathrm{M}$ & $\begin{array}{l}\text { Ampullary well differentiated } \\
\text { adenocarcinoma T2N0M0 }\end{array}$ & Not advised & 36 months & $\begin{array}{l}\text { Splenic flexure colonic } \\
\text { moderately differentiated } \\
\text { adenocarcinoma }\end{array}$ & Metachronous & 18 months \\
\hline 2. & $57 / \mathrm{M}$ & $\begin{array}{l}\text { Ampullary well differentiated } \\
\text { adenocarcinoma T2N0M0 }\end{array}$ & Not advised & 60 months & $\begin{array}{l}\text { Hepatic flexure colonic } \\
\text { moderately differentiated } \\
\text { adenocarcinoma T3N1M0 } \\
\text { with focal mucinous } \\
\text { differentiation }\end{array}$ & Metachronous & $\begin{array}{l}\text { On adjuvant } \\
\text { chemotherapy }\end{array}$ \\
\hline
\end{tabular}


with luminal narrowing in hepatic flexure of colon and biopsy was suggestive of moderately differentiated adenocarcinoma. Patient was diagnosed to have metachronous $2^{\text {nd }}$ primary hepatic flexure colonic adenocarcinoma T3N1M0 and was subjected to right hemicolectomy in 2019. Histopathology was reported as moderately differentiated adenocarcinoma with focal mucinous differentiation. Patient was subjected to adjuvant chemotherapy regime.

\section{Discussion}

Multiple primaries are defined as more than one synchronous or metachronous cancer in the same individual. For medicine studies, tumors are considered multiple primary malignancies if arising in several sites and/or are of a special microscopic anatomy or morphology cluster. This avoids misclassification of multifocal/multicentric tumors or metastases as multiple primaries. A cancer is assessed as index cancer if there has been no prior record of an invasive cancer. The SEER (Surveillance Epidemiology End Results) database recommends using a 2-month period to differentiate between synchronous and metachronous multiple primaries. Rules per the IARC (International Agency for Research on Cancer) suggest the registration of synchronous tumors diagnosed in an interval of less than 6 months (or metachronous if over 6 months) if arising in several sites.

In medicine studies, the frequency of multiple primaries is reported to be within the range of $2-17 \%[7,9]$. Cancer survivors may be vulnerable to developing second primary malignancies because of a variety of distinctive factors, together with cancer predisposition syndromes or special tumor characteristics, environmental exposures and late effects of therapies, Caucasian ancestry, index cancer diagnosed at younger age, lower stage and with typically indolent clinical behaviour with longer survival, as well as positive case history have been reported to harbour excess risk for multiple primaries.

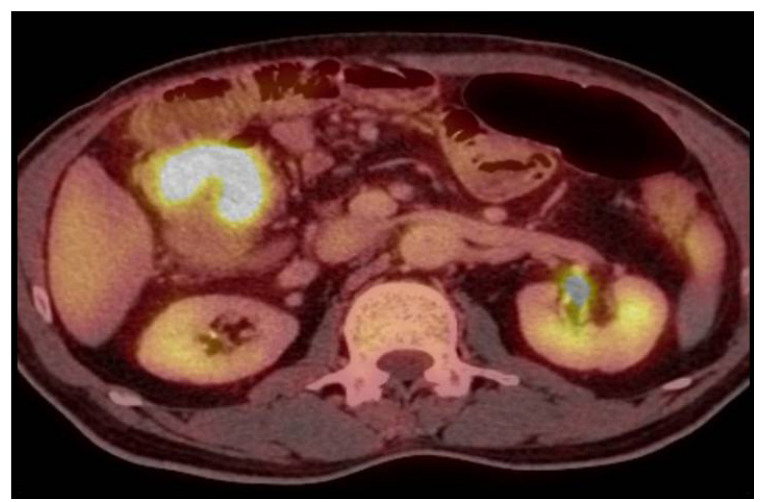

Fig.2: PET CT showing FDG avid lesion in hepatic flexure of colon.

Long-term survival with multiple primaries is variable and is influenced by cancer type and stage at diagnosis. Genetic factors, behavioural influences, lifestyle and co-morbidities typically influencepatient's outcomes. There is a considerably reduced risk of gallbladder cancer after colorectal cancer in both men and women however the chance of second primary colorectal cancer after gallbladder cancer was elevated in both men and women. A considerably elevated risk of colorectal cancer was found in women after bile duct cancer. However, the elevated risk wasn't significant in men. Patients aged fifty years previously diagnosed with colorectal cancer were found to have a relative risk of roughly 2 for the development of ampullary cancer as a second primary malignancy; similar results were discovered for the development of colorectal cancer as a second primary malignancy in patients with ampullary cancer [10]. Patients with malignant disease are more likely than the common person to develop a future malignancy, as a result of genetic status or a standard etiologic agent, or as a consequence of treatment [11]. We therefore suppose that those patients who have undergone surgical procedure for malignant diseases are likely to be diagnosed with a second primary lesion earlier than patients who have had no surgical treatment [12].

Colorectal cancer screening should be strongly considered for people with ampullary 
cancer, because these people are at an elevated risk. In contrast, it's more difficult to determine whether or not patients with colorectal cancer should be screened endoscopically for ampullary abnormalities, particularly because the incidence of ampullary cancer is very low and targeted examination of the ampulla needs side-viewing examination, a specialised technique. Also, it is vital to recognise that certain patient populations are at higher risk of developing multiple primaries, particularly male patients and patients with a history of smoking or alcoholism, patients diagnosed with a primary malignancy at an early stage and lower grade and patients with a hereditary cancer syndrome. Also, the number of octogenarians diagnosed with cancer is increasing and at the same time the frequency of multiple primaries in older patients who are potentially fit enough to receive anti-neoplastic therapy.

\section{Conclusion}

Patients with ampullary cancer have an increased risk of developing a future primary colorectal cancer and that patients with colorectal cancer have an increased risk of developing subsequent primary ampullary malignancy. These findings suggest that ampullary cancer and colorectal cancer may share common environmental and/or genetic risk factors. Given the benefits of colorectal cancer screening, screening colonoscopy should be recommended to patients who have received curative therapy for ampullary cancer.

Acknowledgement: I would like thank my Professor Sankar

S. for guiding and supporting me for this article.

Contributors: NMS: manuscript writing original draft preparation, patient management; SS, SP, NY: critical inputs into the manuscript; patient management. NMS will act as study guarantor. All authors approved the final version of the manuscript and are responsible for all aspects of the study. Funding: None; Competing interests: None stated.

\section{References}

1. Esposito I, Friess H, Buchler MW. Carcinogenesis of cancer of the papilla and ampulla: pathophysiological facts and molecular biological mechanisms. Langenbecks Arch Surg. 2001;386:163-171.

2. Kaiser A, Jurowich C, Schonekas H, Gebhardt C, Wunsch PH. The adenoma-carcinoma sequence applies to epithelial tumours of the papilla of Vater. Z Gastroenterol. 2002;40:913-920.

3. Mahmoud NN, Dannenberg AJ, Bilinski RT, Mestre JR, Chadburn A, Churchill M, et al. Administration of an unconjugated bile acid increases duodenal tumors in a murine model of familial adenomatous polyposis. Carcinogenesis. 1999;20:299-303.

4. Eriguchi N, Aoyagi S, Tamae T, Nishimura K, Hamada $\mathrm{S}$, Kawabada M, et al. Carcinoma of the ampulla of Vater associated with other organ malignancies. Kurume Med J. 2001;48:255-259.

5. Bjork J, Akerbrant H, Iselius L, Bergman A, Engwall $\mathrm{Y}$, Martinsson $\mathrm{T}$, et al. Periampullary adenomas and adenocarcinomas in familial adenomatous polyposis: cumulative risks and APC gene mutations. Gastroenterology. 2001;121:1127-1135.

6. Mecklin JP, Jarvinen HJ, Virolainen M. The association between cholangiocarcinoma and hereditary nonpolyposis colorectal carcinoma. Cancer. 1992;69:1112-1114.

7. Coyte A, Morrison DS, McLoone P. Second primary cancer risk - the impact of applying different definitions of multiple primaries: results from a retrospective population-based cancer registry study. BMC Cancer. 2014;14:272.

8. Weir HK, Johnson CJ, Thompson TD. The effect of multiple primary rules on population-based cancer survival. Cancer Causes Control. 2013;24:1231-1242.

9. Rosso S, De Angelis R, Ciccolallo L, et al. Multiple tumours in survival estimates. Eur J Cancer. 2009;45:1080-1094.

10. Das A, Neugut AI, Cooper GS, Chak A. Association of ampullary and colorectal malignancies. Cancer. 2004;100:524-530.

11. Kattlove H, Winn RJ. Ongoing care of patients after primary treatment for their cancer. CA Cancer J Clin. 2003;53:172-196.

12. Eriguchi N, Aoyagi S, Hara M, Okuda K, Tamae T, Fukuda S, et al. Synchronous or metachronous double cancers of the pancreas and other organs: Report on 12 cases. Surg Today. 2000;30:718-721. 